\title{
Study on Vegetable Field Evaluation Index System for Non-Point Source Pollution of Dagu River Basin
}

\author{
Jinheng Zhang ${ }^{1}$, Junqiang Wang ${ }^{2}$, Yongliang $\mathrm{Lv}^{1}$, Jianting Liu ${ }^{1}$, Dapeng $\mathrm{Li}^{1}$, \\ Zhenxuan $\mathrm{Yao}^{1}$, Xi Jiang ${ }^{1}$, and Ying Liu ${ }^{1}$ \\ ${ }^{1}$ Institute of Eco-environment \& Agriculture Information, \\ School of Environment and Safety Engineering, Qingdao University of Science and Technology, \\ Qingdao, Shandong 266042, China \\ ${ }^{2}$ Qingdao Station for Popularizing Agricultural Techniques, Qingdao, Shandong 266000, China
}

\begin{abstract}
This research combined data from soil, terrain and meteorological surveys, with quantitative data from soil and water field studies to determine the leaching processes of nitrogen and phosphorus contaminants from field vegetation into the Dagu River. Using the Gray correlation analysis method, precipitation and irrigation were established as the major driving force behind leaching losses from cultivated land. The type of fertilizers used, and the chemical and physical properties (porosity and bulk density) of soils in the region were set as parent sequences. COD values of nitrogen and phosphorus concentration were calculated from soil and water samples. Also, the depth of core samples was factored into the analysis. The result showed that the supply of soil nitrogen and phosphorus, which were mainly derived from fertilizers, were not generally high levels in Qingdao. According to fuzzy association degree, this investgation confirmed main influencing factors which affected COD, total nitrogen, total phosphorus of soil and groundwater, ammonia nitrogen and nitrate nitrogen of groundwater respectively. And according to these factors the initial vegetable field evaluation index system for non-point source pollution of Dagu River basin was constructed.
\end{abstract}

Keywords: Gray correlation analysis, Nitrogen, Phosphorus, COD, Precipitation, Soil physical properties, Soil type, Index system.

\section{Introduction}

Excessive nitrogen and phosphorus values used in fertilization will significantly decreases the economic benefits of enhanced crop production, as well as increases the risk of nitrogen and phosphorus contaminants in water reserves [1-3]. Approximately, 60\% of water pollution is caused by non-point source NPS) pollution in America [4]. In the Northern Australia, NPS pollution flowing into water reserves is also the major source of nitrogen contamination [5]. In Denmark, 94\% of the nitrogen load and 52\% of the phosphorus load in 270 rivers is a result of non-point source processes [6]. The same effects can be seen in the Netherlands, where $60 \%$ or the total nitrogen contaminants and $40-50 \%$ of the total phosphorus contaminants are caused by NPS pollution [7]. 
In recent years, as agricultural development mirrors population growth in China, NPS pollution has become the main source of water pollution. Currently, China contains 1600 million $\mathrm{hm}^{2}$ of cultivated land, which amounts to $35 \%$ of the agricultural land on the planet [8]. Statistics measuring the amount of fertilizers, livestock and poultry manure and the cultivated land area from 2000 to 2006 in Qingdao were investigated. Subsequently, an index was established to evaluate the nitrogen and phosphorous content in livestock manure as NPS pollutants [9]. A Grey Correlation study to evaluate water pollution from vegetable fields in the Dagu River Basin of Qingdao[10].

Over the years, the Dagu River has become increasingly more important to the national economy and to the lives of local residents. However, as the region surrounding the Dagu River Basin is developed, pollution of the river has become increasing obvious. It is the fertilizers and pesticides that have aided the agricultural development that threaten the water reserves. The numerous and excessive applications of fertilizers and pesticides cause soil erosion and serious water pollution from increasing nitrogen and phosphorus concentrations. This study integrates data from soil, terrain and meteorological surveys of Dagu River basin, with quantitative analysis studies of thousands of soil samples to construct an indexing system of NPS pollutants entering the Dagu River. The Dagu River is located in the western Shandong Peninsula, between $120^{\circ} 03^{\prime} \sim 120^{\circ} 25^{\prime} \mathrm{E}$ and $36^{\circ} 10^{\prime} \sim 37^{\circ} 12^{\prime} \mathrm{N}$ and covers an area of $4631.3 \mathrm{~km}^{2}$ in Qingdao. The river runs through five districts in Qingdao, Laixi City, Pingdu, Jiaozhou, Chengyang, Jimo (see Figure 1). The annual precipitation in the region is about 685.3 $\mathrm{mm}$ and an annual runoff is about $6.311 \times 10 \mathrm{~m}^{3}$ [11].

\section{Materials and Methods}

\subsection{Sample Collection}

For this study, soil and water samples were collect in December of 2009 from cultivated land throughout the region (Figure 1). The samples of vegetable field soil were divided into two categories, surface soil $(0-20 \mathrm{~cm})$ and submerged soils $(80-100 \mathrm{~cm})$. Additionally, surface water and ground water samples were collect from the same areas. GPS was used to map the latitude and longitude of sample areas. All samples were analyzed in the laboratory, using quantitative methods.

\subsection{Sample Analysis}

To determine the COD of water samples, they were heated in a strongly acid solution, containing potassium dichromate. A Euro Tech ET3150B multiple digester and an ET1151M COD Monitor were used for characterization. $\mathrm{K}_{2} \mathrm{~S}_{2} \mathrm{O}_{8}$ digestion molybdenum blue colorimetry was used alongside the COD digester to analyze the total concentration of phosphorus in samples. Nitrite has a visible absorption at $220 \mathrm{~nm}$, so a 752SP UV was used to measure its concentration in aqueous samples. Nessler's reagent was added to pretreated samples, and, then, a spectrometer was used to measure their absorbance at $420 \mathrm{~nm}$. Also, oxidation-ultraviolet spectrophotometry was used to 
determine the total nitrogen content of samples, after the addition of potassium sulpersulthephate at $120 \sim 124^{\circ} \mathrm{C}$.

Soil samples were first treated with alkaline potassium persulfate. Then, UV spectrophotometry was used to measure each solutions absorbance at $220 \mathrm{~nm}, 275 \mathrm{~nm}$ and $700 \mathrm{~nm}$ to measure their total nitrogen and phosphorus content. Potassium dichromate was added to soil samples before COD analysis.

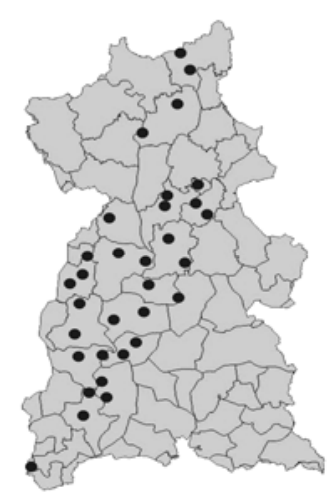

Fig. 1. Soil samples distribute

\section{Results and Analysis}

\subsection{The Main Source and Loss of Non-point Source Pollution}

Fertilizer, irrigation, and atmospheric deposition are the main sources of nitrogen and phosphorus in cultivated land within the basin. Among these, fertilizers are the most abundant source of the elements. There was a large quantity of $\mathrm{NO}_{3}{ }^{-} \mathrm{N}$ in samples, as it is in not readily absorbed by soil colloid [12]. Rainfall and irrigation contributed to the loss of accumulated $\mathrm{NO}_{3}{ }^{-} \mathrm{N}$, via surface run-off (procedure $\mathrm{C}$ in figure 2) and/or through leaching (procedure A and B in figure 2) [13],[14].

\subsection{The Substance Basis of Fertilizer Leaching and Driving Force of Vegetable Field Soil Nitrogen and Phosphorus}

A classification system was developed from the analysis of more than 7000 soil samples, which were classified on the bases of total nutrient content. Results were classified into six categories based on nitrogen supply level from vegetables. The data is shown in table 1.

We analyzed more than 1000 soil samples and classified the soluble phosphorus content. Results showed that very high soluble phosphorus supply level of vegetable land was only $7.83 \%$, but general and lower supply level were $76.99 \%$ (Table 2). 
Table 1. Classification total nitrogen in soil (Data from Qingdao soil, edited by the Soil and Fertilizer Workstation of Qingdao City)

\begin{tabular}{cllll}
\hline \multirow{2}{*}{ supply level } & \multicolumn{2}{c}{ Upland area } & \multicolumn{2}{c}{ field } \\
& \multicolumn{2}{c}{ acre } & \multicolumn{2}{c}{ Vegetable land } \\
\hline high & - & - & - & - \\
extremely high & 5938 & 0.07 & 10174 & 3.16 \\
general & 1060672 & 12.14 & 211928 & 65.78 \\
lower & 4830122 & 55.31 & 100042 & 31.06 \\
low & 2676373 & 30.65 & - & - \\
extremely low & 160226 & 1.83 & - & - \\
\hline
\end{tabular}

Table 2. Classification soluble phosphorus in soil (Datas from < Qingdao soil > edited by the Soil and Fertilizer Workstation of Qingdao City)

\begin{tabular}{ccccc}
\hline \multirow{2}{*}{ Supply level } & \multicolumn{5}{c}{ field } \\
\cline { 2 - 5 } & \multicolumn{2}{c}{ Upland area } & \multicolumn{2}{c}{ Vegetable land } \\
\cline { 2 - 5 } & acre & $\%$ & acre & $\%$ \\
\hline high & - & - & - & - \\
higher & - & - & 25207 & 7.83 \\
general & 277110 & 3.17 & 147990 & 45.93 \\
lower & 1797677 & 20.58 & 129624 & 40.24 \\
low & 3419031 & 39.15 & 19323 & 6 \\
extremely low & 3239513 & 37.1 & - & - \\
\hline
\end{tabular}

From the above statistics, we found that nitrogen and phosphorus supply level in Qingdao vegetable land were not very high. Additionally, fertilizer was the main source of nitrogen and phosphorus. Subsequently, it was reasonable to study fertilizer as a basic source of fertilizer leaching. Meteorological precipitation data combined with crop irrigation were overwhelmingly contributed to the leaching loss of nitrogen and phosphorus from soil.

\subsection{Determine Leaching Loss Factors of Nitrogen and Phosphorus according to Grey Relational Analysis}

Types of fertilizer and soils, the physical properties of different soils (porosity and bulk density), precipitation data, soil nitrogen and phosphorus content, and soil COD were indexes in the analysis of leaching nitrogen and phosphorous. Gray correlation was used to analyze the effect of these indexes on the contaminant concentrations in the local water reserve. An index system based on well-correlated factors related to nitrogen and phosphorous loss from agricultural soil was established. The factors are 
listed below, in decreasing order: ammonia content, nitrate content, total nitrogen of groundwater, soil type, soil porosity (from shallow to deep), soil bulk density (from shallow to deep), precipitation, soil COD and soil total nitrogen content. Fertilizer plays the most significant role in affecting the quality of groundwater, followed by soil physical properties and soil chemical properties. The order of factors affecting total phosphorus content of groundwater was soil type, soil phosphorus content, soil COD, phosphate fertilizer of per hectare, soil porosity (from shallow to deep), soil bulk density (from shallow to deep) and precipitation, respectively. Phosphorus leaching from soil was the main source of phosphorus in groundwater.

\subsection{Single Factor Assessment Index of Non-point Source Pollution}

\subsubsection{Fertilizer Grade of Nitrogen and Phosphorus Leaching Loss}

Compound fertilizer, with similar nitrogen and phosphorous contents commonly used fertilizers, was applied to survey region (total nitrogen content $15 \%$ according to $\mathrm{N}$, total phosphorus content $15 \%$ according to $\left.\mathrm{P}_{2} \mathrm{O}_{5}\right)$. The result from formula $(1,2)$ gave a mean value of fertilizer in survey region of $150.7 \mathrm{~kg} / \mathrm{hm}^{2}$. The standard deviation was 139.6 .

Mean value:

$$
\bar{x}=\frac{\sum_{i=1}^{n} x_{i}}{n}
$$

Standard Deviation:

$$
\sigma=\sqrt{\frac{\sum_{i=1}^{n}\left(x_{i}-\bar{x}\right)^{2}}{n}}
$$

Probability Density:

$$
f(x)=\frac{1}{\sqrt{2 \pi} \cdot \sigma} e^{-\frac{(x-\bar{x})^{2}}{2 \sigma^{2}}}
$$

According to probability density calculations (figure 2), the second center should be considered as the average nitrogen concentration in fertilizer per hectare in every season. The standard deviation was divided into five intervals: $0 \sim 80,80 \sim 220,220 \sim 360$, $360 \sim 500$ and $>500 \mathrm{~kg} \cdot \mathrm{hm}^{-2} \cdot$ season $^{-1}$ (see table 4). An advantage of this division was that similar values can be drawn in same level, which reduces the risk that similar dispersed within the data.

\subsubsection{The Precipitation Grade of Nitrogen and Phosphorus Leaching Loss}

When long-term soil leaching occurs, the optimum conditions were as follows: the effects of the sum of precipitation and irrigation are more than the effects of the sum of run-off, evaporation and good soil infiltration. Conditions of short-term soil leaching 
mirrored large amount of precipitation or irrigation [15]. In the study area, precipitation is heaviest from June to August, about 500mm, which accounts for more than $50 \%$ of the annual precipitation. In the summer irrigation was lessened, due to the increase precipitation.

In this analysis, 200mm precipitation was used as the lower limit and was divided into 5 levels in $100 \mathrm{~mm}$ intervals. Short-term soil loss reached measurable level when single precipitation/irrigation events exceeded $50 \mathrm{~mm}$ (see the table 5).

Table 3. Sequence of gray correlation Table 3a

\begin{tabular}{cccc}
\hline & Ammonia Nitrogen & $\begin{array}{c}\text { Groundwater } \\
\text { Nitrate Nitrogen }\end{array}$ & Total Nitrogen \\
\hline Nitrogen fertilizer & 1 & 1 & 1 \\
Soil type & 2 & 2 & 2 \\
Soil porosity & & & \\
shallow layer & 3 & 3 & 3 \\
medium layer & 4 & 4 & 4 \\
deep layer & 5 & 5 & 5 \\
Soilbulk density & & & 6 \\
shallow layer & 6 & 6 & 7 \\
medium layer & 7 & 7 & 8 \\
deep layer & 8 & 8 & 9 \\
Precipitation & 9 & 9 & 10 \\
COD of soil & 10 & 10 & 11 \\
Soil total nitrogen & 11 & 11 & 6 \\
\hline
\end{tabular}

Table 3b.

\begin{tabular}{cc}
\hline & TP of groundwater \\
\hline soil type & 1 \\
Soil total phosphorus & 2 \\
COD of soil & 3 \\
Nitrogen fertilizer & 4 \\
Porosity (deep layer) & 5 \\
Porosity (medium layer) & 6 \\
Porosity (shallow layer) & 7 \\
bulk density (shallow layer) & 8 \\
bulk density (deep layer) & 9 \\
bulk density (medium layer) & 10 \\
Precipitation & 11 \\
\hline
\end{tabular}




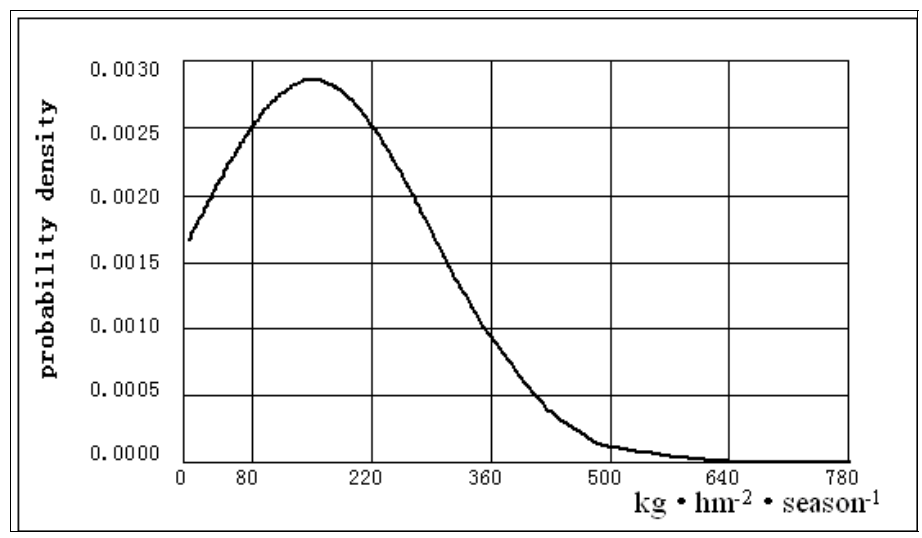

Fig. 2. Probability density function of fertilization

Table 4. Fertilizer grade of nitrogen and phosphorus leaching

\begin{tabular}{|c|c|c|}
\hline $\begin{array}{c}\text { Compound } \\
\text { fertilizer } \\
\left(\mathrm{kg} \cdot \mathrm{hm}^{-2} \text {.season }\right. \\
\end{array}$ & Grade & Description \\
\hline$<80$ & $\mathrm{~F} 1$ & $\begin{array}{l}\text { Fertilizer less than the average fertilizer level. The substance } \\
\text { basis of leaching loss was not enough, and the leaching loss } \\
\text { won't be happened. }\end{array}$ \\
\hline $80 \sim 220$ & F2 & $\begin{array}{l}\text { Fertilizer was near the average amount. On the occasion of } \\
\text { heavy rain or over-irrigation, light leaching loss will be hap- } \\
\text { pened. }\end{array}$ \\
\hline $220 \sim 360$ & F3 & $\begin{array}{l}\text { The light leaching loss will be happened. The degree will } \\
\text { increase according to rate of fertilizer and water. }\end{array}$ \\
\hline $360 \sim 500$ & F4 & $\begin{array}{l}\text { Middle leaching loss level. But heavy leaching loss can be } \\
\text { happened. The rate of fertilizer is more than average rate. }\end{array}$ \\
\hline$>500$ & F5 & (Super) heavy leaching loss level. \\
\hline
\end{tabular}

Table 5. Driving factor grade of nitrogen and phosphorus fertilizer leaching

\begin{tabular}{lll}
\hline $\begin{array}{c}\text { Precipitation } \\
\left(\mathrm{mm} . \text { season }^{-1}\right)\end{array}$ & grade & \multicolumn{1}{c}{ description } \\
\hline$<200$ & W1 & $\begin{array}{l}\text { Shortage of precipitation. The general leaching loss won't be } \\
\text { happened. }\end{array}$ \\
$200 \sim 300$ & W2 & $\begin{array}{l}\text { Precipitation met the requirements of leaching loss. Light leaching } \\
\text { loss may be happened. }\end{array}$ \\
$300 \sim 400$ & W3 & $\begin{array}{l}\text { Precipitation met the requirements of leaching loss. Light leaching } \\
\text { loss may be happened. } \\
\text { Precipitation was adequate, and moderate leaching loss may be } \\
\text { happened. } \\
\text { Precipitation was extremely adequate, and heavy leaching loss } \\
\text { may be happened. }\end{array}$ \\
\hline 500 & W5
\end{tabular}




\subsubsection{The Soil Type Grade of Nitrogen and Phosphorus Leaching Loss}

Soil type played an important role in leaching loss. Under similar conditions, clay soil showed minimum nitrogen and phosphorus leaching loss, whereas, the largest nitrogen and phosphorus leaching loss was from sand soil. Medium loss was observed in loam soil [16],[17]. The soils of Dagu River, which can be used to cultivate vegetables, are brown earth, aquic brown earth, brown paddy soil, cinnamon soil, eluvial cinnamon soil, developed cinnamon soil, lime concretion black soil, and fluvo-Aquic soil. Nitrogen and phosphorus leaching loss was divided into three categories, according to an analysis of the physical property of the soils, including total soil porosity and soil bulk density (see table 6).

Table 6. The soil type grade of nitrogen and phosphorus leaching loss

\begin{tabular}{ccl}
\hline Soil type & grade & \multicolumn{1}{c}{ description } \\
\hline brown earth & - & $\begin{array}{l}\text { It widely distributes in the hill, valley and the front slope of mountain. The } \\
\text { land is thick, and there is clayey layer generally. It played reduced role on } \\
\text { nitrogen and phosphorus leaching loss. }\end{array}$ \\
$\begin{array}{c}\text { aquic brown } \\
\text { earth }\end{array}$ \\
brown paddy \\
soil
\end{tabular}
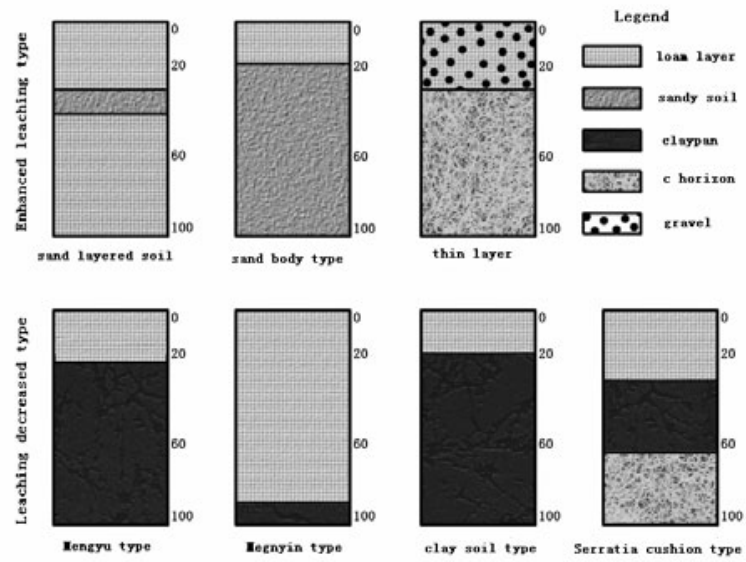

Fig. 3. The Soil Body Configuration of nitrogen and phosphorus leaching loss 


\subsubsection{The Soil Body Configuration Grade of Nitrogen and Phosphorus Leaching Loss}

According to results of table 5, when sandy soil is present in the upper layer, leaching will occur more readily. On the contrary, when clay soil is present, leaching will be respectively lower. Consequently, we classified the nitrogen and phosphorus leaching loss according to the soil composition. Areas of sand-layered and thin-layered soil were classified as enhanced nitrogen and phosphorus leaching loss types. Clay layered, intercalated clay layered, Mengyu type, and Mengyin type soils were as classified as reduced nitrogen and phosphorus leaching loss types.

\section{Conclusions}

Fertilizer was as the main source of nitrogen and phosphorus NPS pollution. Precipitation was the most significant driving force of leaching loss of nitrogen and phosphorous in regional soils. The application of fertilizer is the most significant contributor to nitrogen content in groundwater, followed by the physical and chemical properties of regional soils. The results showed that the most influential factors determining the total nitrogen content of groundwater was the soil type, chemical properties of the soil, phosphorus content, the physical properties of the soil, and precipitation, respectively. The amount of nitrogen per hectare and the precipitation in a season were divided into five levels respectively. Nitrogen and phosphorus leaching loss per soil type was classified as follows, enhanced grade, reduced grade and uncertain grade. Soil body configurations of nitrogen and phosphorus leaching loss were classified as enhanced and reduced grades.

Acknowledgments. Project supported by the Science and Technology Projects of Qingdao (08-2-1-36-nsh and 09-1-1-53-nsh).

\section{References}

1. Xing, G.X., Shi, S.L.: Situation of nitrogen pollution in water bodies in SuZhou region. Acta Pedologica Sinica 38(4), 540-545 (2001)

2. Xiong, Z.Q., Xing, G.X.: Non-point $\mathrm{N}$ pollution of lakes, rivers and wells in the Taihu Lake region. Rural Eco-Enivironment 18(2), 29-33 (2002)

3. Xu, Q.X., Meng, Z.F., Yu, C.H.: Approaches for reduction of nitrate contamina $\neg$ tion on vegetable by appropriately applying fertilizers. Agro-environmental Protection 19(2), 109-111 (2000)

4. Corwin, D.I., Wagenet, R.J.: Application of the Modeling of non-point Sources Pollutants in the vadose zone. Journal Environment Quality 25, 403-411 (1996)

5. Griffin, J.R.: Introducing NPS Water Pollution. EPA Journal, 6-9 (November /December 1991)

6. Kronvang, B.: Diffuse nutrient losses in Denmark. Water Science Technology 133, 81-88 (1996)

7. Boersp, C.M.: Nutrient emissions from agriculture in the Netherlands: causes and remedies. Water Science Technology 33(1), 183-190 (1996) 
8. Feng, H.X., Yang, X., Li, X.Y., Wang, M.Z.: The effects of continuous cropping of vegetables on the biochemical properties of soil. Journal of ChangJiang Vegetables 11, 40-43 (2004)

9. Zhang, J.H., Wang, J.Q., Wan, Y., Han, C.: Agricultural non-point source pollution investigation and assessment in Qingdao. Chinese Agricultural Science Bulletin 26(10), 276-280 (2010)

10. Zhang, J.H., Wang, J.Q., Liu, J.T., Yao, Z.X., Li, D.P.: Evaluation of surface water pollution in Qingdao vegetable area based on gray correlation method. Shandong Agricultural Sciences 5, 78-82 (2010)

11. Zhou, G.Z., Zhang, J.H., Wang, J.Q., Li, J.: Application of the fuzzy mathematics in evaluation Dagu River water quality. Journal of Agro-environment Science 29(suppl.), 191-195 (2010)

12. Zhang, G.L., Zhang, S.: Advances of cropland Nitrogen Leaching. Soil 6, 291-297 (1998)

13. Liu, J.L., Li, R.G., Liao, W.H.: The yield response of vegetable to phosphate fertilizer and soil Phosphorus accumulation in a Chinese Cabbage-capsicum Rotation. Scientia Agricultura Sinica 38(8), 1616-1620 (2005)

14. Shi, C.Y., Zhang, F.D., Zhang, J.Q.: Change of soil nutrients under greenhouses under long-term fertilization condition. Plant Nutrition and Fertilizer Science 9(4), 437-441 (2003)

15. Johnes, P.J.: Evaluation and management of the impact of land use change on the nitrogen and phosphorus load delivered to surface waters, the export coefficient modeling ap $\neg$ proach. Journal of Hydrology 183, 323-349 (1996)

16. Chen, S.G.: Dry calcareous soil characteristics and nitrogen volatilization loss of ammonia Channels. Agricultural Research in the Arid Areas 3, 28-37 (1988)

17. Chen, X., Jiang, S.Q., Zhang, K.Z., Bian, Z.P.: Law of phosphorus loss and its affecting factors in red soil slopeland. Journal of Soil Erosion and Soil and Water 5(3), 38-41, 63 (1999) 